\title{
Positioning the Destination Product - Can Regional Tourist Boards Learn from Private Sector Practice?
}

This article examines the role of positioning in the marketing of a tourism destination. The study focuses on the current positioning strategies pursued by the Regional Tourist Boards (RTBs) in England. A recent nationwide consumer research study into short holiday destination choice in the $U K$ revealed that consumers were confused by the regional product message. The evidence suggests that current RTB positioning strategies are failing to keep pace with the constantly evolving needs of the consumer. This article explores the reasons for clearly positioning the destination product and suggests that, although RTBs could learn from marketing strategies employed in other sectors of the tourism industry, there are likely to be organisational and cultural barriers inhibiting this learning curve.

\section{Positioning}

Lovelock describes positioning as the process of establishing and maintaining a distinctive place in the market for an organisation and/or its individual product offerings (Lovelock 1991). This process, developed by Lovelock is illustrated in figure 1 below.

\section{INSERT DIAGRAM.}

To develop a positioning strategy there are three procedures which a service organisation must follow: market analysis; internal analysis; and competitor analysis. 
Service managers need to ask themselves the following questions. What is our service concept? How does it differ from competitive offerings? How well does it meet the needs of customers in different market segments?

Lovelock argues that positioning services involves developing and communicating key product attributes, and is not primarily about creating advertising images. In contrast to image, position requires a frame of reference, which is provided by competitive destinations (Crompton 1992). It is a stage subsequent to market segmentation at which the marketer determines which of the visitor target market's important needs a destination is better able to service than its competitors. Positioning is concerned with three issues: the segmentation decision, image, and selection of a destination's features to emphasise (Aaker and Shansby 1982). Aaker and Shansby place their emphasis on segmenting the market and then matching the product to the needs of those segments. This approach is also taken by Woodside (1982) who suggests that the key to successful positioning is matching the benefits provided by a destination with benefits sought by a target market considering that destination. This relationship between product attributes and benefits sought is evident in Kotler's explanation of product branding, a subject area closely allied to positioning. Kotler sees branding as having six levels of meaning: attributes; benefits; values; culture; personality; and user (Kotler 1994).

To apply the positioning process in figure one to destination marketing, the marketer must first research the market to ascertain which product attributes determine destination choice. Based on a realistic strengths and weaknesses assessment of the destination and its competitors, the decision can then be made as to which market segments to target and with which products. In listing the principal uses 
of positioning, Lovelock views distribution, pricing and communication strategies as progressing naturally from clear product positioning.

\section{Positioning a Destination - Problems and Challenges}

Positioning a destination presents a number of challenges, two of which are inherent in marketing a service "product", namely intangibility and inseparability. Intangibility leads to consumer uncertainty. Unlike a good which Lovelock describes as an 'object, a device, a thing,' the service product can be more aptly described as 'a deed, a performance, an effort.' When considering destination marketing, the word "experience" could be added, as the destination marketer is effectively selling tourist experiences. However, Ryan makes a distinction between holidays and other services. The tourist has a degree of control over the purchase, in that he/she can dictate their level of involvement with different elements of the service, for example destination attributes, activities and people. In this way the tourism purchase differs from, say, a retail service situation.

Despite this higher level of consumer participation in the tourism purchase, the holidaymaker will still perceive an element of risk during the initial buying process. In her study of the consumer evaluation process, Zeithaml hypothesised that consumers perceive greater risks when buying services than when buying goods (Zeithaml 1990). It needs to be added however that the degree of perceived risk is dependent on the price of the purchase, the benefits which the consumer expects to derive from the purchase, and whether or not the consumer has purchased the same or a similar service in the past. According to marketing theory derived from the 1960s (eg Sheth), if the price of the service is low then the perceived risk of financial loss is low. It is 
arguable however in the case of tourism that the cost of the purchase cannot be measured in financial terms alone - even a short break holiday requires the expenditure of valuable leisure time, at a time when there are ever increasing demands on disposable leisure time. Therefore, although this short break may involve relatively little financial outlay, the level of expectation may be quite high. Zeithaml supports her study of risk with two additional hypotheses: consumers adopt innovations in services more slowly than they adopt innovations in goods; and consumers seek and rely more on information from personal sources than from non personal sources when evaluating services prior to purchase. Consumers are naturally more cautious when purchasing something which they cannot touch, experience, test, or experiment with and which is unlikely to come with a guarantee or warranty.

Because of the intangible nature of a destination, an explicit positioning strategy is valuable in helping prospective visitors to get a "mental fix" on it that may otherwise be amorphous (Lovelock 1984). For example, consider the challenge facing the North West Tourist Board, one of eleven RTBs in England. The northwest region of England offers a wide range of tourist experiences - major cities, upland and lowland countryside, historic towns and villages, seaside resorts and undeveloped coastline. How does the tourist board communicate such a diverse product to the visitor? The North West Tourist Board concede in their 1994/5 strategy document that the product is too diverse to market as one entity and that they will aim instead to market individual products and themes. It could be argued that tour operators face a similar problem as they are effectively selling a destination. However if a customer books a one week holiday in Greece with Thomson Holidays, the largest tour operator in the UK, he is buying a clearly defined Thomson product. The reality is that little of Greece is actually being marketed to the customer. Even with the growth in 
independent travel packages, the customer is primarily buying an identifiable branded product.

The challenge posed by intangibility is compounded by the lack of consistency in buyer behaviour within market segments. Visitor expectations can vary radically. For example two families on an identical short break package may record very different levels of satisfaction with the holiday, because they had different expectations and were looking for different benefits from the package. This is in contrast to most consumer goods where the product has a given set of attributes and customers' expectations can be more readily identified.

The second challenge relates to the inseparability of the service production and consumption processes. This can result in inconsistencies in the quality of the product and its delivery. The supplier of manufactured goods can put the product through a rigorous test period before distribution and consumption. This helps to avoid costly mistakes arising from customer dissatisfaction with the product. The tourism supplier does not have this opportunity as the production and consumption of the product take place simultaneously. This potential for inconsistency in delivering the destination product is compounded by the high level of human involvement in the production process.

The challenge posed by inseparability is arguably stronger for the destination marketer than for the service product marketer, due to the lack of control which is exercised over the many suppliers of the tourism product. The multitude and diversity of tourism suppliers in the destination makes quality control and cohesion a difficult task. Many of these suppliers are small to medium-sized enterprises, often family run and with little formal training. Generally there is no commercial relationship between the RTB and the suppliers and the RTB can only exercise control through measures 
such as training, providing information and advice, and by grading and classification. By contrast most major tour operators, through vertical integration strategies, exercise a high degree of control over their suppliers and therefore over the customer's holiday experience. This enables them to deliver a more consistent product.

\section{RTB Positioning in England}

In order to evaluate current RTB positioning the author poses three questions based on Lovelock's positioning process. Firstly, what evidence is there that the RTBs have undertaken market, internal, and competitor analyses? Secondly, how have their analyses translated into clear market segmentation, differentiation from the competition and the identification of customer benefits? Thirdly, how has this positioning process materialised itself in terms of product offerings? In order to gain an insight into key issues, the author supplemented his desk research by mailing a largely open-ended questionnaire to each RTB marketing manager. Seven out of eleven RTBs responded.

Few organisations would dispute that knowledge of the market underpins successful marketing. In the author's survey the marketing managers were asked what consumer information they collected to assist them in the production and distribution of the main regional brochure. In addition to recording consumer response and conversion, half the respondents indicated that they collected a full range of consumer information - demographics, past buyer behaviour and intentions to buy. Half the respondents also claimed to collect holiday-taking trend information. When asked how this information was used to develop product message and offerings, the 
responses were general rather than specific, with respondents indicating that the information was analysed and used and that market knowledge underpins the product. The author concedes that in-depth interviews may have gained more specific responses.

Internal analysis by the RTBs is informal and ongoing. When asked to assess the strengths and weaknesses of their product and marketing strategies the most popular responses revealed an interesting dilemma. On the one hand more than half the respondents replied that their product range was a strength, while on the other hand the same proportion indicated that trying to be all things to all people was a weakness. This point highlights a key factor affecting RTB policy, namely that they are heavily dependent on their commercial members and local authority members for funding. Attraction owners, accommodation providers and smaller districts within the region, all naturally want as much profile for their products as possible. The problem is that this orientation may not necessarily correspond to the needs of the consumer.

Six RTBs undertake a competitor analysis once per year. Five were able to specify individual UK regions as competitors. No overseas destinations were specifically named as competitors.

The second stage in evaluating RTB positioning is to assess the effectiveness of the above analyses in leading to accurate market segmentation, competitive differentiation and the identification of customer benefits. A study of the RTB strategy documents provides some insight. There is an emphasis on market segmentation. The Yorkshire and Humberside Tourist Board refers to the 50+ age group, educational and study tours, and activity holidays. The Northumberland Tourist Board segments the market by socio-economic criteria and by region and country of residence. Competitors are not referred to explicitly, however a common aim is to create a positive image for the 
destination. The East Midlands Tourist Board places particular emphasis on image and talks of the need to develop a brand identity for the region.

The findings of the English Tourist Board (ETB)-commissioned 1991 survey, referred to in the abstract, indicate that the RTBs are out of touch with the real needs of the consumer and unable to identify customer benefits. The survey examined the factors influencing the choice of destination by UK residents for short holidays of 1-5 nights in paid accommodation in Britain (MEW Research 1991). The findings indicated that holidaymakers were most likely to be influenced by a type of holiday or activity, whereas the RTBs were promoting regions, local areas or towns. Inspection of the RTB strategies does indicate that they are aware of this weakness. The majority of RTBs refer to the need to develop specific products and themes, for example literary and heritage promotions. The West Country Tourist Board and the Yorkshire and Humberside Tourist Board stress the need to aim these products at specific market segments.

The initial two stages of Lovelock's positioning framework are in many respects a means to an end. The destination product is the manifestation of this positioning process. In order to truly complete the stage two evaluation of RTB positioning it is necessary to move to the final stage and study the actual product offering. The author has chosen the RTB brochures as the framework for this product analysis. The justification for this framework lies in the fact that the brochure effectively is the product from the consumer's viewpoint. The only tangible means by which a visitor or consumer can assess which tourism products a destination is offering is by studying the brochure which that destination makes available. A study of tourist motivation revealed that just over 50 per cent of respondents based their choice of destination solely on the information provided in travel brochures. These people belonged to all 
socio-economic classes (Mansfeld 1992). There are three reasons why the tourism brochure plays such an important role in the decision-making process: a trip is a high risk purchase and involves the use of discretionary dollars during an individual's free time; the consumer is unable to actually observe the potential purchase, therefore secondary or tertiary sources must be used; and holiday makers tend to visit new and relatively unfamiliar destinations as a primary motivation to travel (Wicks \& Schuett 1991).

In their strategies the majority of RTBs refer to their region or destination as the overall product. With the exception of one RTB this manifests itself in the annual production of a main regional brochure, containing the region's range of tourism products. Results from the MEW Research study found that respondents considered RTB brochures to be confusing and that tour operator brochures were of more relevance in helping them to select a destination. The findings indicate that consumers prefer to use operators' brochures principally because they relate to the way individuals already think about their holidays. Operators' brochures specialise in the type of holidays people want, whether it be an activity brochure, say a Golf World Handbook, or an accommodation agency, say English Country Cottages. It appears that the RTB brochure primarily served the function of providing information once the destination had already been chosen. This is a notable weakness given that studies undertaken by Stabler (1989) and Etzel and Wahlers (1984) demonstrate that tourists rely more on informational material while preparing their trip at home than after arriving at their destination.

On the whole the RTBs continue to produce their main regional brochure, generally trying to be "all things to all people," a weakness which several RTBs are aware of. The author's survey revealed that RTBs view the role of the regional brochure as 
creating and retaining awareness and generating new business. The main holiday brochure produced by each RTB is an amalgam of all the region's tourism products and is distributed to all enquirers through different channels. Generally the RTB publications do not attempt to break the overall destination down into distinct product offerings or themes. No single brochure attempts to offer a combination of benefits to the visitor. As with the main brochure the other publications produced by the RTBs do not relate to visitor activities or type of holiday, but rather are a reflection either of the nature of the tourism suppliers or of geographic location. Brochure titles on offer cover places to stay, bed and breakfast touring map, places to visit, seaside resorts, farm holidays, attractions guide, pub guide, events guide. As mentioned earlier, this orientation is a necessity given the nature of tourist board funding. At the same time visitor attractions and tourist areas are plural products in that they can offer different people different benefits. Arguably, this is also true for larger accommodation providers. It is possible therefore that pluralist marketing could meet the need for recognition of the RTB member and the consumer's need for a relevant and identifiable product. Although this pluralist marketing approach would require the production of multiple brochures, it is arguable that smaller, more targeted brochures would be more cost effective in the longer term.

There is evidence that some RTBs are adopting this position. The South East Tourist Board has produced two new publications for 1994/5 entitled "Walking/Cycling Holidays" and "Visual Arts and Crafts". The West Country Tourist Board has produced a guide to activity and leisure holidays. The Southern Tourist Board no longer focuses its attention on a main regional guide, preferring instead to forge leads through database marketing campaigns. 


\section{Positioning in Other Tourism Sectors}

Key players from the hospitality and tour operating sectors have pursued major repositioning and product development strategies. Both the processes and the results of these strategies provide potential insights for the RTBs. The development of Courtyard by the Marriott hotel group pioneered the use of new research and product development techniques. The development process involved the following stages: selection of a product development team; environment and competitor analysis; customer analysis; idea generation; product refinement; product positioning; and monitoring of results (Crawford-Welch 1994). The environment and competitor analysis identified a gap in the market. The remaining stages were underpinned by extensive consumer research, based around defining preferred product attributes and benefits. Seven sets of attributes were identified: external factors; rooms; food-related services; lounge facilities; services; leisure facilities; and security factors. A range of individual product attributes were developed within each of these sets. A range of multivariate and inferential statistical analyses were used by Marriott, including conjoint, cluster analysis, multidimensional scaling, and multiple discriminant analysis. The exercise has proved a success for Marriott with the Courtyard brand expanding from three test hotels in 1983 to more than 200 in 1994.

Forte Hotels also harnessed internal and external expertise to research the market and identify key benefit-seeking market segments as part of their restructuring process in 1991. This form of benefit-related segmentation has been studied in depth by Vavrik and Mazanec (1990) who also refer to it as A posteriori segmentation. Using multivariate statistical techniques, individuals are aggregated into groups which seek similar benefits. This kind of analysis is useful, as the tourism manager is likely to be 
interested in determining which groups or segments would support a given product category; how the segments differ in their responsiveness to a range of product offerings (brands, destinations, etc.) within that category; and how they differ in their expectations (Calantone and Mezanec 1991).

Several distinct brands were created under the Forte umbrella. One of the overall aims of the Forte rebranding exercise was to provide reassurance to customers when choosing hotels in different destinations (Connell 1994). In other words the rebranding of the hotels attempted to reduce consumer's perceived risk when purchasing a Forte product.

Two further objectives of the Forte rebranding exercise were, firstly, to offer a clear position in an expanding international market and, secondly, to help employees identify themselves better with the company and to make them understand their contribution towards the corporate effort. This second objective recognises the inseparability of the production and consumption processes and the integral part which hotel staff represent in the delivery of the overall product. Connell observes that as a result of the rebranding Forte is now able to communicate the differences between brands to make it easier for customers to choose the hotel they need.

The Forte repositioning exercise is typical of the general trend in the international hotel market towards greater product segmentation, defined by Pannell Kerr Forster Associates as the development by hotel companies of new accommodation concepts designed to meet the needs of specific target markets without depleting their existing core products (1990). This product segmentation strategy is a means of stimulating demand in a market which is steadily slowing in growth. Pannell Kerr Forster Associates list 'consumer acceptance' as one of the factors which encourages product segmentation. Products are developed which identify the changing needs of the 
consumer and are perceived by the consumer as offering a better price/value relationship. The benefits of the Forte branding exercise have extended beyond the consumer. Firstly, the more clearly positioned brands have enabled management to cater more effectively to their specific market segments. Secondly, the rebranding has resulted in more product consistency which has been welcomed by distributors serving the different markets (Connell 1994).

The potential offered by clear product positioning has not been lost on the tour operation industry. The 1994 restructuring of Owners Abroad, then the second largest tour operator in the UK, was a bold move which slimmed the previous range of seven brands down to three and renamed the company First Choice Holidays. There were a number of weaknesses, revealed in the company's relaunch literature, which initiated this repositioning strategy. Firstly, many of the brands had no clear positioning, competed with one another, and had low consumer awareness and loyalty. Secondly, the company's organisational structure reflected the brand structure - unwieldy and fragmented. Thirdly, the company name itself had no consumer recognition, could not be used as an umbrella brand and its use, for example at airport check-ins and information desks was confusing to holidaymakers. The company name did not even properly reflect the nature of the business.

Each of the three brands has a clear distinctive positioning which is based on extensive consumer research. In addition to being the umbrella brand, First Choice is the mass-market brand, price-oriented and aimed primarily at the family market. Each holiday product within this brand features kids' clubs designed to give parents free time, and are a key part of the First Choice proposition. First Choice have even branded the children's clubs; 'Nippers' is for 3-6 year olds, 'Surf Seekers', for 7-11 year-olds, and 'Beach Hounds', for 12-16 year-olds. 
First Choice claim a number of key benefits have resulted from their rebranding strategy: it enables them to respond to consumer trends more flexibly and effectively; they will be able to expand or improve their product range rapidly within each brand category whilst maintaining the continuity of the main brand names; good brands will help build the corporate image; and it will be easier for distributors to handle the product and advise customers.

Certain differences between RTBs and commercial companies such as First Choice Holidays require that a degree of caution be exercised before making hasty comparisons. The earlier section on the unique challenges facing the destination marketer has already referred to one key difference in respect of ownership and control of the product. The accountability of the RTB to it's commercial and local authority members, some of whom may not be particularly sophisticated in their thinking, represents a significant restriction. It is arguable that this restriction results in marketing officers having to fulfill a number of functions not related to marketing. There are additional differences. Firstly, the commercial companies referred to in this article will have greater financial and human resources at their disposal. Secondly, and perhaps most significantly, is the more competitive and customer-orientated culture evident in the commercial company. This is partly a reflection of the different external environments in which the two types of organisation have developed. In today's fluctuating and highly competitive business environment the commercial company must adapt to survive. Hence, within months of Francis Baron's arrival as Chief Executive of First Choice Holidays there was a complete restructuring of the organisation. This would be a difficult task to achieve in the political and not-forprofit public sector environment in which the RTB operates. 


\section{Repositioning the Destination Product}

This last section considers the arguments for repositioning the regional destination product and looks at ways in which this could be done. Consumer demand is the most potent argument for a reappraisal of RTB positioning strategies. Consumers' holiday expectations are becoming increasingly more sophisticated, with the market breaking down into increasingly smaller segments. The challenge facing the RTB is how to reach the right segment with a relevant and easily identifiable destination product. The traditional "shotgun" approach of trying to be all things to all people is becoming increasingly redundant. The first step in this repositioning process is to undertake a reappraisal of the market, in line with Lovelock's positioning process. The MEW Research study identified six key market segments which they labelled as follows: Cities and Culture; Brogues and National Trust; Sports n' Interests; Rural Relaxation; Kids Rule OK; and Out for a Good Time. As the names suggest, the demographic profile and preferred activities vary from segment to segment. For example, the "Cities and Culture" segment show an above average interest in historic cities or towns and cultural sites, whereas the "Out for a Good Time" segment express most interest in nightlife and eating out. This study was commissioned by the ETB for the RTBs, however there is little evidence to suggest that the findings have been taken on board.

All seven RTBs who responded to the author's survey currently have a customer database. These enquirers, and repeat visitors in particular, represent an RTB's most valuable market and provide an ideal test ground for undertaking similar quantitative and qualitative research to that undertaken by MEW Research. This could be conducted in-house or by an external agency. Obviously cost is a significant constraint, however a partnership approach with local tourism suppliers may prove a 
cost-effective solution. A market analysis should go beyond demographic profiling. RTBs need to identify market segments which are looking for similar benefits from a holiday experience. Segmentation based on benefits desired is usually the most meaningful type to use from a marketing standpoint as it directly facilitates product planning, positioning and advertising communications (Young, Ott, and Feigin 1978). The segmentation process could be further refined by capturing psychographic data, incorporating lifestyle, attitudes, values and interests. As a means of fine-tuning their customer profile the RTB could employ the services of one of several companies in the UK which, using their own extensive lifestyle databases, specialise in the profiling and enhancement of customer databases. A recent innovation in this area is a profiling product called Psyche, developed by the credit rating company $\mathrm{CCN}$, which has identified seven consumer segments with distinct personal value profiles: Self Explorers; Experimentalists; Conspicuous Consumers; Belongers; Social Resisters; Survivors; and Aimless. Research by Madrigal and Kahle (1994) reveals the importance of personal values in the destination selection process. The data in their research indicate that although demographic differences existed across segments, personal value systems were better predictors of activity preferences. Madrigal and Kahle observe that this information would be valuable in determining how a destination should position itself in the marketplace. Promotional themes could connect a destination's activities and attractions with personal values relevant to specific target markets.

The second step in this repositioning process is to undertake a realistic strengths and weaknesses assessment of the destination and develop appropriate products to offer to the relevant market segments. This requires close co-operation with tourism suppliers in the region. Middleton (1988) believes destination marketing organisations 
have two strategic alternatives. Firstly, they can concentrate their budget on creating tourist motivations and attitudes through image campaigns. The second alternative is to follow a strategy of facilitating and influencing suppliers of the tourism product. He firmly believes, given the limited public sector budget, that the latter course will produce more tangible results. The MEW Research study reveals that respondents already have a perception of many regions in England and of the types of holiday available at those destinations. The authors of the study advise that any attempt to change these perceptions in the short term would be unrealistic. They conclude that the best way to change people's preconceptions of a destination is to focus marketing activity on types of holiday rather than types of people. A partnership between the RTB and regional tourism suppliers would facilitate the development of tourism activity packages. This partnership would be similar to the product development team approach taken by Marriott. By sharing the results of the market analysis with tourism suppliers and inviting them to participate in the product planning process, the RTB can also undertake a more realistic internal (i.e. destination) strengths and weaknesses assessment than they would be able to if the suppliers felt excluded from the process. A detailed competitor analysis is an essential part of this repositioning process, if the RTB is to successfully differentiate its destination from that of its competitors. Again the market analysis will help to facilitate this third step. Having identified the key target segments, customers could be asked what other destinations they travel to, why they travel there, likes and dislikes, etc.

This repositioning process would enable the RTBs to develop a more focused marketing mix based on a detailed market, internal and competitor analysis. As with the Marriott approach to the development of the Courtyard concept, there has to be ongoing monitoring and refinement of the positioning process, which requires 
continuous market intelligence. The development of comprehensive marketing and product databases would be an effective means of achieving this. The power of the personal computer now enables the destination marketing officer to store and analyse profiling information on a large volume of customers. In the author's survey of the RTBs, five out of seven respondents access their customer database only once per year. An effective marketing database, combining demographic, psychographic, transactional, campaign performance and other related marketing data, could provide the ongoing market intelligence needed to monitor positioning. Similarly, continual feedback from the product development team could be used to develop and continuously upgrade a product database.

Any repositioning process will require change, particularly in the culture of the organisation and management attitudes. It is to some extent a "chicken and egg" situation as many companies cite organisational factors when talking of the benefits of repositioning. In his case analysis of British Airways, Torin Douglas emphasises the internal organisational benefits of the airline's restructuring in the late 1980s (Lovelock 1991). Douglas observes that branding helps build motivation, improves lines of communication within the organisation and encourages staff to identify with their particular brand. To reinforce the repositioning of their tourism products the RTBs could adopt an organisational structure based on a brand management approach. The American Marketing Association defines a brand as a name, term, sign, symbol, or design, or a combination of them, intended to identify the goods or services of one seller or group of sellers and to differentiate them from those of competitors (Kotler 1994). Following this branding approach, an RTB would allocate staff to each of its products, much in the same way that British Airways allocate a team to each of their brands. This brand management approach would present several advantages. Firstly, it 
would enable staff to develop detailed knowledge of their particular market segments, thereby continuing to focus on benefits required by the consumer. Secondly, RTB staff could develop closer working relationships with the suppliers and distributors of the product. This partnership approach is expressed by several RTBs in their strategic plans. Particular emphasis is placed on packaging and presenting the product for distribution by the travel trade. RTBs could move much closer to the facilitator role envisaged by Middleton. For example they could initiate joint marketing schemes, suggest new product developments, provide training, give marketing support and make available customer data. The Heritage ' 84 campaign undertaken by the British Tourist Authority to market Britain overseas illustrates this point. It shows how creative theming can influence the tourist industry, regardless of the size of the financial resources to be put into advertising by the National Tourist Office (Middleton 1988). Thirdly, the RTBs would have more readily identifiable product areas to manage. In the author's survey, lack of control over the product and a diverse product range were both cited by the RTBs as strategic weaknesses. The fourth advantage lies in improved monitoring of marketing activity. With more focused product areas and market segments, the RTBs could more accurately measure the effectiveness of their marketing activities. A campaign performance section could by built into a marketing database to measure enquiries, cost per enquiry, conversion of enquiries into sales, and so on. National Tourist Offices need to refine and develop their methods of measuring the effectiveness of their destination marketing (Lavery 1992). The same holds true at regional level. The printing and distribution of the main regional tourist guide represents a major slice of the RTB marketing budget, yet they have little means of gauging the effectiveness of this publication, other than receiving general feedback from suppliers, distributors and information gathered through 
surveys. This lack of accountability makes the allocation of resources something of a hit-and-miss strategy. This is a serious problem considering their restricted budgets.

\section{Conclusion}

Clear product positioning must be an integral part of any destination marketing strategy, due to the inherent characteristics of the destination product and the increasingly complex needs of the tourist. Key players in the hospitality, tour operator and airline sectors have pursued successful positioning strategies which have been driven by effective market segmentation and brand management. This begs the obvious question as to why the RTBs have not incorporated similar policies into their marketing strategies. The answer to this question is, arguably, to be found in the organisational culture of the RTBs. Detailed market, competitor and internal analyses will act as a catalyst for positive organisational change as well as leading to improved positioning and marketing. This change cannot be achieved overnight, however a gradual repositioning process, combined with strong partnerships with their members, would enable the RTBs to address a significant number of their organisational, operational and financial constraints. 


\section{REFERENCES}

Aaker, D.A., \& Shansby, J. (1982, May-June). Positioning Your Product. Business Horizions, pp. 56-62.

Calantone, Roger \& Josef Mazanec (1991). Marketing Management and Tourism. Annals of Tourism Research, (Vol.18) 101-119.

Connell, John (1994). Repositioning Forte Hotels Portfolio. English Tourist Board Insights, (March) C43-51.

Crompton, John L. (1992). Positioning: The Example of the Lower Rio Grande Valley in the Winter Long Stay Destination Market. Journal of Travel Research, (No. Fall) 20-26.

Etzel, M., \& Wahlers, R.G. (1984). The Use of Requested Promotional Materials by Pleasure Travellers. Journal of Travel Research, (No.23) 2-6.

Kotler, Philip (1994) Marketing Management: Analysis, Planning, Implementation and Control. 8th ed., Englewood Cliffs, NJ: Prentice Hall.

Lavery, Patrick (1992). The Financing and Organisation of National Tourist Offices. Travel \& Tourism Analyst, (No.4) 84-101.

Lovelock, C. H. (1984). Services Marketing. Englewood Cliffs, NJ: Prentice-Hall.

Lovelock, Christopher H. (1991). Services Marketing. 2nd ed., Prentice- Hall.

Mansfeld, Y. (1992). From Motivation to Actual Travel. Annals of Tourism Research, (Vol.19) 399-419.

MEW Research (1991). Holiday Destination Choice, Qualitative Report. BTA/ETB Research Services, London.

Middleton, Victor (1988). Marketing in Travel and Tourism. Heinemann, Oxford. 
Pannell Kerr Forster Associates (1990). Hotel Product Segmentation in Europe. English Tourist Board Insights, (November) A

Stabler, Mike (1988). The Image of Destination Regions: Theoretical and Empirical Aspects. In B. Goodall \& G. Ashworth (Eds.), Marketing in the Tourism Industry (pp.133-161). London: Croom Helm.

Vavrik, U and J Mazanec (1990). A priori and A posteriori Market Segmentation: Tailoring Automatic Interaction Detection and Cluster Analysis for Tourism Marketing. Cahiers du Tourisme, Serie C, No.62 Aix-en-Provence: Centre des Hautes Etudes Touristiques.

Wicks, Bruce E., \& Michael Schuett (1991). Examining the Role of Tourism Promotion Through the Use of Brochures. Tourism Management, (December) $301-313$.

Woodside, A.G. (1982). Positioning a Province Using Travel Research. Journal of Travel Research, (No.20 Winter) 2-6.

Zeithaml, Valarie A. (1990). Delivering Quality Service: Balancing Customer Perceptions and Expectations, New York: Free Press. 